\title{
Planning an academic conference Another form of service
}

W

hile librarians are often involved in planning library conferences or other professional development activities, few organize academic conferences. It is an aspect of academic service that is often overlooked but can benefit your library and your campus, as well as create a stronger tie between the two.

We organized Buffy to Batgirl: Women and Gender in Science Fiction, Fantasy, and Comics in May 2014, at Rutgers University-Camden. The two-day conference attracted more than 150 participants, pri-

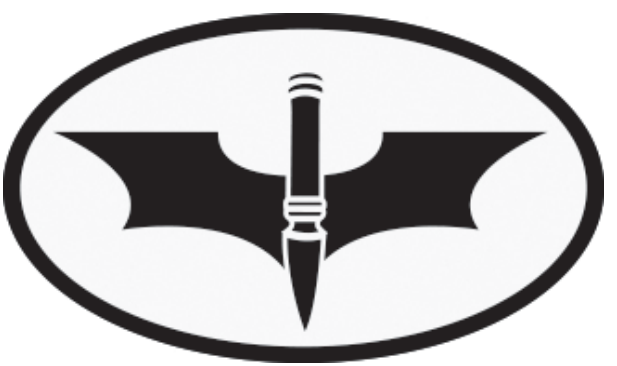

Buffy to Batgirl logo. Rutgers UniversityCamden/Beatris Santos. marily non-librarians, including 80 speakers from four countries. Buffy to Batgirl increased local and national visibility of our campus and received positive feedback from speakers and attendees. While we had a tremendous amount of assistance from campus event staff, we handled all the academic arrangements (selecting speakers, organizing panels, and making sure things went smoothly). This level of librarian involvement created additional goodwill for the library on campus.

Buffy to Batgirl was based on Pippi to Ripley: The Female Figure in Fantasy and Science Fiction, a conference organized by Katharine Kittredge and Elizabeth Bleicher at Ithaca College. Kittredge and Bleicher encouraged the participation of speakers from all levels of academia, from senior scholars to undergraduates and independent scholars. Panels were arranged with no separation on the basis of degree or institution. Pippi to Ripley, held in both 2011 and 2013, had already inspired one daughter conference. Katniss to Catwoman: Villainesses and Heroines of Fantasy and Science Fiction was held at Middle Tennessee State University in 2012. No one had indicated an interest in having such a conference in 2014, and Kittredge encouraged us to consider doing so.

Shortly after returning, we saw an announcement that our then-chancellor was requesting proposals for a series of Chancellor's Signature Events. With the approval of our library director, we submitted a proposal for a conference similar to Pippi to Ripley, which would be held the following May, and it was accepted. We sat down with Events Office staff and created a general timeline. They knew how to coordinate a large event but were not familiar with the

Julie Still is reference librarian, email: still@rulmail.rutgers. edu, and Zara Wilkinson is reference librarian, email:zara. wilkinson@camden.rutgers.edu, at Rutgers UniversityCamden

() 2015 Julie Still and Zara Wilkinson 
academic aspects, while we were familiar with academic conferences but knew next to nothing about event planning.

In the months that followed, we received a crash course in planning an academic conference. We found that there are three general areas of activity: academic arrangements, local arrangements, and branding. Depending on the availability of dedicated event-planning staff, a conference organizer may be involved in some or all of these areas.

\section{Academic arrangements}

- Call for papers. A call for papers (CFP) lists basic conference information (place and date), the focus of the conference and suggested areas of research, and submission instructions that include the deadline. Where you distribute your call will depend on your topic. We advertised on a popular humanities CFP site maintained by the University of Pennsylvania English Department and the Science Fiction Research Association email list. It was reposted to a variety of other sites, including some in other countries, which may have helped attract international speakers.

Setting up an email account for the conference can help avoid having messages get lost in your regular work email. Having a separate account will also facilitate future communication with your applicants, as you will need to send out both acceptance and rejection letters. Rejecting a paper proposal is not an enjoyable task. Remember to be gracious, thank the person for his or her interest, and encourage the writer to pursue other options with their research.

- Panels. Even once you have a selection of promising speakers, arranging them into panels can be a daunting task. We found the easiest way to do this was to lay each abstract out on a table (or the floor) and then literally stack them into groups of three or four based on topic and theme. Once you add working titles, these stacks become panels. As you organize your panels into a schedule, remember to leave time between sessions for people to take breaks, get from one room to another, and network.

- Moderators. Closer to the conference, you will want to find moderators for each panel. The moderator can be a speaker, either in the same panel or another panel, or a faculty member or student from your institution. The primary roles of a moderator are to introduce speakers, handle questions, and, if there is not a separate timekeeper, let speakers know when their time is ending and cut them off if they go over. We invited Rutgers University-Camden graduate students to act as moderators, providing them with a great opportunity to participate and a scholarly activity to put on their $\mathrm{cv}$.

\section{- Keynote and all-conference events.}

A keynote speaker, if your conference has one, can be a scholar or well-known person with some expertise on the topic. The conference budget will dictate if you can offer to pay travel expenses or to provide an honorarium. A keynote is only one kind of all-conference event; others include film viewings, receptions, and networking sessions. For example, we held an afternoon screening of the documentary Wonder Women! The Untold Story of American Superheroines. Because all-conference events are important opportunities for participants to meet and interact, it is recommended that every conference have at least one.

\section{Local arrangements}

- Budget. Setting up a budget was a crucial step that defined how the rest of the conference would be run. We were fortunate to be awarded two small internal grants. Holding the conference on campus provided a greater opportunity for university buy-in, and we sought financial or in-kind cosponsorships from other campus offices and departments. These included the Women's and Gender Studies Program, the Office of Campus Involvement, and, of course, Rutgers University Libraries. Even with funding, we knew we would have to 
charge for registration in order to cover all of our costs. We considered this very carefully because we knew it could potentially discourage part of our intended audience. To best include students and the local community, and to follow the example set with Pippi to Ripley, we decided to charge speakers a nominal fee while allowing all others to attend free of cost, but registration was required.

- Food. The best way to ensure attendance at any event is to provide food, and academic conferences are no exception. The amount of food you can provide your attendees depends on your budget. If your conference is on campus, you may be required or strongly encouraged to use campus catering services. We found campus catering to be a good choice, although there were unanticipated costs for set up and clean up. They were also able to accommodate dietary requirements by providing vegetarian and gluten-free options. Not all meals need to be catered, especially if there is a campus cafeteria or nearby restaurants. You can encourage your attendees to explore your campus or surrounding area. Conference organizers, however, may want to pack a lunch or order in advance, as it is unlikely they will be able to get away.

We provided a continental breakfast both mornings in order to ensure that the conference could get started on time. The first day, we gave all attendees a list of local restaurants and food trucks for lunch. Our campus is very invested in the surrounding community, so we were glad to support local businesses as much as possible. The owners of one popular food truck have expressed how much they appreciated the extra business and later donated a gift certificate as a prize for an unrelated library contest. The second day, which was a Saturday, we arranged an all-conference lunch because fewer businesses are open on the weekend. We also offered a cookie reception during the keynote speech, and the Office of Campus Involvement donated cupcakes from a nearby bakery to accompany our film screening.

- Lodging. If your conference attracts interest from scholars outside of the geographic area, you will most likely have to help your attendees with housing and transportation. At the very least, you should provide the names and contact information of hotels in the area. Your college or university may have existing arrangements for reduced rates. We were able to offer low-cost dormitory accommodations to a limited number of people. That was a great option for graduate students and international attendees whose airfare was already very expensive.

- Transportation. You should also provide recommendations for transportation to campus from major airports and train stations, as well as from conference hotels. As part of the terms of our Signature Events grant, we arranged shuttle service between selected hotels and campus. Details about public transportation options in the area and campus parking arrangements should also be provided.

- Registration. We were able to work with the campus Events Office to create a conference email address, website, and online registration site. The registration site allowed us to accept credit cards, track details such as dietary requirements, and maintain a current database of conference attendees.

The physical registration desk presented another issue. Having a conference organizer at the desk to greet people and answer questions is ideal, but it may mean that the organizers cannot attend many sessions. We recommend creating a staffing schedule before the event. If possible, you should recruit students or colleagues to assist.

- Technical requirements. As the date of the conference approaches, you will need to clearly communicate with your presenters regarding their technical needs. You will have to find out whether the presentation rooms have computers, 
projection equipment, and Internet access. Some speakers will want to use their own laptops, but some may prefer to bring their presentation on a flash drive, if the option is available. If possible, see if a tech person can be on site during the conference, so you won't have to be the person checking on cables and figuring out why the sound won't work.

\section{Branding}

- Visual image. Our conference logo and website, which were created for us by a web designer in the campus Communications Office, allowed us to advertise the conference on flyers and social media. We used the logo on every item associated with the conference: website, conference program, nametags, and buttons given to all attendees.

- Associated scholarship. A wellplanned and executed conference can lead to other scholarly activity. You might want to repeat the conference in the future or you might want to invite your presenters to contribute to a conference proceedings or a special issue of a journal. We are currently working on an edited book featuring papers from Buffy to Batgirl.

- Related events. There were related events on campus, including a library display. Since then, we have held Buffy to Batgirl events at other campus functions, such as Camden Comic Con. Continuing the brand allows us to advertise similar events to interested participants in our geographic area and creates further opportunities for the library to participate in campus activities.

- Public relations. Although an academic conference is primarily focused on scholarship, it can nonetheless be used to generate publicity for your library and your campus. Notifying local press about a conference or event can lead to positive news stories about the university. After the conference, you can send library and campus administrators a detailed report that includes conference goals and how they were met and any press clippings, including examples of social media coverage. Asking participants to fill out an evaluation will provide you with good feedback and quotes for your report.

Organizing a conference is a very demanding, frustrating, time-consuming, and exhilarating task. Overall, it presents an invaluable opportunity to strengthen the bond between the library and the campus, heighten the academic profile of the library and librarians, and create another scholarly brand for the college or university.

\section{Additional reading}

1. Cynthia Shamel, "So you want to hold a conference: Event planning resources," Searcher (July/August 2012): 12-39.

2. Brian Lucey, "How to organise an academic conference-10 tips," The Guardian, January 17, 2014. Available at http:// www.theguardian.com/higher-educationnetwork/blog/2014/jan/17/how-to-organise-academic-conference. $\boldsymbol{n}$

\section{ACRL-Choice webinars}

The ACRL-Choice webinar program connects academic and research librarians with content and service providers, publishers, and other experts. Upcoming topics include:

Library Technology Essentials (September 10, 2015-sponsored by Rowman \& Littlefield)

Positioning your Library Marketing for Success (September 15, 2015-sponsored by Springer)

Watch for information on additional ACRLChoice webinars coming this fall.

Additional information on the program, along with registration links and an archive of past webinar recordings, is available on the Choice website at www.choice 360. org/acrl-choice-webinars/events. 